\title{
DE MINÚSCULOS TITÃS A LEGIONÁRIOS QUE QUEIMAM: A REPRESENTAÇÃO DE FORMIGAS NAS ANIMAÇÕES INFANTIS
}

\author{
FROM TINY TITANS TO LEGIONARIES WHO BURN: \\ THE REPRESENTATION OF ANTS IN THE CARTOON
}

\author{
DE PEQUEÑOS TITANES HASTA LEGIONARIOS QUE ARDEN: \\ REPRESENTACIÓN DE HORMIGAS EN ANIMACIONES INFANTILES
}

\author{
Sheila Alves de Almeida ${ }^{1}$ (D) $(2$ \\ Marco Antônio Alves Carneiro ${ }^{2}$ (D) 9 \\ Orlando Gomes Aguiar ${ }^{3}$ (D) 9 \\ Maykon Passos Cristiano 4 (D) 9
}

\begin{abstract}
RESUMO
Este estudo objetivou compreender as representações de formigas em animações infantis. Para isso, assistiu-se a cada animação mais de uma vez para perceber como as formigas foram significadas nos desenhos animados. Daí, foram registrados dados recorrentes e singulares na representação das formigas nos desenhos. Para a análise do objeto de pesquisa, a estrutura narrativa da animação e a estrutura conceitual da gramática visual inspiraram a construção de categorias. Os resultados indicaram que os desenhos animados analisados exploraram as características e os comportamentos humanos como base para a construção de personagens e narrativas. Observou-se que as animações abordam aspectos morfológicos das formigas, mas o comportamento delas ainda é pouco explorado e evidenciado. As concepções culturais da sociedade humana e seus preconceitos foram recorrentes em todas as animações estudadas.
\end{abstract}

Palavras-chave: Representação de formigas. Desenho animado. Ensino de Ciências.

\begin{tabular}{l} 
ABSTRACT \\
This study aimed to understand the representations of ants in children's animations. For that, we watched \\
each animation more than once to understand how ants were meant in cartoons. Hence, recurring and \\
singular data were recorded in the representation of ants in the drawings. For the analysis of the research \\
object, the narrative structure of the animation and the conceptual structure of the visual grammar \\
inspired the construction of categories. The results indicated that the cartoons analyzed explored human \\
\\
\hline${ }^{1}$ Doutora em Educação pela Universidade de São Paulo (USP). Professora Associada da Universidade Federal de \\
Ouro Preto (UFOP). Ouro Preto, Minas Gerais, Brasil. Campus Morro do Cruzeiro, Bairro Bauxita, Ouro Preto, \\
MG, Brasil 35.400.000. E-mail: sheilaalvez@ufop.edu.br. \\
${ }^{2}$ Doutor em Ecologia, Conservação e Manejo da Vida Silvestre pela Universidade Federal de Minas Gerais \\
(UFMG). Professor Associado da Universidade Federal de Ouro (UFOP). Campus Morro do Cruzeiro, Bairro \\
Bauxita, Ouro Preto, MG, Brasil 35.400.000, E-mail: marco.carneiro@ufop.edu.br. \\
${ }^{3}$ Doutor em Educação pela Universidade Federal de Minas Gerais (UFMG). Professor Titular da Universidade \\
Federal de Minas Gerais (UFMG), Belo Horizonte, Minas Gerais, Brasil. Endereço para correspondência: \\
Av. Antônio Carlos 6627, Pampulha - Belo Horizonte, MG - Brasil. E-mail: orlando@fae.ufmg.com.br. \\
${ }^{4}$ Doutor em Genética pela Universidade Federal de Viçosa (UFV). Professor Adjunto da Universidade Federal de \\
Ouro Preto (UFOP), Ouro Preto, Minas Gerais, Brasil. Campus Morro do Cruzeiro, Bairro Bauxita, Ouro Preto, \\
MG, Brasil 35.400.000. E-mail: maykon@ufop.edu.br.
\end{tabular}

Universidade Federal de Mato Grosso, Cuiabá, Mato Grosso, Brasil. Revista REAMEC - Rede Amazônica de Educação em Ciências e Matemática, v. 9, n. 1, e21007, janeiro-abril, 2021. 
characteristics and behaviors as a basis for the construction of characters and narratives. It was observed that the animations address the morphological aspects of the ants, but their behavior is still little explored and evidenced. The cultural conceptions of human society and its prejudices were recurrent in all the studied animations.

Keywords: Ant representation. Cartoons. Science Education.

\section{RESUMEN}

Este estudio tuvo como objetivo comprender las representaciones de hormigas en animaciones infantiles. Para eso, vimos cada animación más de una vez para entender cómo se entendían las hormigas en los dibujos animados. Por lo tanto, se registraron datos recurrentes y singulares en la representación de las hormigas en los dibujos. Para el análisis del objeto de investigación, la estructura narrativa de la animación y la estructura conceptual de la gramática visual inspiraron la construcción de categorías. Los resultados indicaron que las caricaturas analizadas exploraron características y comportamientos humanos como base para la construcción de personajes y narrativas. Se observó que las animaciones abordan los aspectos morfológicos de las hormigas, pero su comportamiento aún está poco explorado y evidenciado. Las concepciones culturales de la sociedad humana y sus prejuicios fueron recurrentes en todas las animaciones estudiadas.

Palabras clave: Representación de hormigas. Dibujos animados. Educación Científica.

\section{INTRODUÇÃO}

Nas sociedades modernas e pós-modernas, a maior parte da população dos países desenvolvidos concentra-se nas cidades. Nesse ambiente urbano, crianças, jovens e adultos, criados longe do meio ambiente natural geralmente têm contato com animais domésticos e insetos. Entretanto, a maior parte dos insetos são vistos pelos humanos como seres repugnantes, vetores de doenças, sempre associados ao lixo e à sujeira. É o caso das baratas, moscas, pernilongos, mosquitos e formiga.

Segundo Boccaro et. al (2015), apesar da quantidade e diversidade de insetos existentes no planeta, os mais lembrados são as formigas e as baratas, talvez pela frequência desses insetos nos ambientes. As formigas se destacam das baratas pela abundância, diversidade e pela maior "aceitação" delas pelos humanos nos ambientes domésticos. Várias espécies de formigas se adaptaram ao dia a dia das cidades, por exemplo, as encontradas nos açucareiros (BOCCARO, 2015). Provavelmente, são os primeiros animais com que os humanos têm contato durante a vida. Frequentemente somos surpreendidos com formigas caminhando em fila ora na cozinha, sobre a mesa, pias, nas lixeiras, no escritório, ora nos jardins carregando folhas e pétalas de plantas ornamentais; ora entre tijolos, azulejos e até dentro de aparelhos eletrônicos. Também carregam carcaças de outros insetos. Segundo crenças populares, as formigas "são boas para as vistas"; sinalizam mudança de vida quando surgem na entrada das casas; e nos sonhos, significa 
prosperidade financeira. Formigas também simbololizam a vida em grupo, o trabalho, a cooperação, a parcimônia, a resistência e o esforço. Usadas em sentido figurado podem representar crítica à sociedade humana moderna e pós-moderna. Talvez por isso há uma profusão de filmes de animação sobre a vida das formigas.

Embora o problema da representação de animais nos filmes de animação não seja novo nem recente, acredita-se, ainda ser relevante um estudo sobre as animações, uma vez que elas proliferam também nas telas dos computadores, tablets e celulares encantando crianças e adultos. Ademais, a maioria dos estudos acerca das representações dos animais nos filmes de animações analisa as diferentes espécies sem destacar um grupo. Em geral os estudos sobre a representação dos animais ignoram as questões animalescas (VIZACHRI, 2000). As pesquisas evidenciam, principalmente, as discussões relativas ao gênero e às relações de poder em detrimento da compreensão das características biológicas e comportamentais dos animais.

Tendo em vista essas questões e considerando o número de animações sobre as formigas, optou-se pela análise de produções em que esses insetos são representados. Ao assistir às animações que descrevem a vida no formigueiro e a interação entre as formigas, foram construídas referências sobre esses insetos. Foi possível perceber as diferentes representações das formigas nas telas ao longo das décadas. As narrativas em torno da vida das formigas se desenvolvem em meio às várias cenas que deixam marcas de concepções sobre o "mundo das formigas" e o "mundo dos humanos" em uma construção historicamente situada.

Afinal, a presente pesquisa teve por objetivo investigar como as formigas são representadas nos desenhos animados. Para tanto, assistiu-se a cada animação mais de uma vez para que fosse possível compreender como esses insetos são significados nos desenhos. As categorias de análise foram inspiradas nos estudos sobre a morfologia e comportamento das formigas (BACCARO e et. al, 2015) e nos estudos sobre multimodalidade (KRESS e VAN LEEUWEN 2006). Esse quadro teórico permitiu identificar quais traços são ressaltados ou ignorados nas representações que retratam as formigas nas animações.

\section{REFERÊNCIAL TEÓRICO}

\subsection{Breve estudo sobre as formigas}

As formigas formam um grupo bem delimitado e diversificado. Elas são amplamente distribuídas, encontradas em todos os continentes, exceto nas regiões polares. Atualmente, são conhecidas mais de 13 mil espécies de formigas, pertencentes a uma única família (Formicidae), e distribuídas em 17 subfamílias (Bolton, 2020). 
Embora existam diferentes espécies de formigas, pode-se fazer algumas generalizações sobre sua biologia. Elas são organismos eussociais, o que quer dizer que todas as espécies de formigas vivem em uma sociedade organizada, com divisão de trabalho entre as operárias e a rainha, que apresenta função reprodutora, sobreposição de gerações e por fim, um cuidado cooperativo com a prole (HÖLLDOBLER \& WILSON, 2009). As castas das formigas são divididas em operárias e reprodutoras. As operárias são estéreis e responsáveis em cuidar da colônia, incluindo a coleta de alimentos, cuidado com a rainha e com a prole (HÖLLDOBLER \& WILSON, 2009). A casta de reprodutores é composta por fêmeas e machos, que, na maioria das espécies, são aladas. Essa casta é produzida em determinada época, quando a colônia chega a sua maturidade (BACCARO, et al., 2015). Após emergirem, tanto a fêmea como o macho saem da colônia materna para um voo nupcial. O macho, após fecundar a fêmea, morre, pois, sua função é apenas de reprodução, e a rainha, por sua vez, desce ao solo, retira suas asas e começa a escavar para construir seu ninho (BACCARO et al. 2015). Dentro da sua nova casa, a rainha inicia a postura dos ovos que, depois de algumas semanas, emergirão em operárias que começarão a auxiliar a rainha na tarefa de construção de uma nova colônia (BACCARO et al. 2015). Diferente de como o senso comum prega, as rainhas não são uma fonte de liderança explícita.

As formigas nascem de ovos e desenvolvem-se por metamorfose completa, passando por um estado larval, equivalente à lagarta dos outros insetos e pelo estado de pupa. As larvas e pupas precisam de temperatura constante para se desenvolverem e, por isso, são transferidas para câmaras diferentes dentro do formigueiro, de acordo com o seu estágio de desenvolvimento.

As formigas desempenham um importante papel no meio ambiente. Algumas espécies espalham sementes, ajudam a adubar o solo. Algumas se alimentam de partes de frutos e animais em decomposição. Assim como as minhocas, as formigas ajudam o solo a ficar mais rico ao cavar túneis e remexer a terra fazendo com que o ar da superfície entre em contato com as camadas mais profundas do solo. As formigas são, em sua maioria, carnívoras e se alimentam de outros animais invertebrados vivos ou mortos. Dessa maneira, elas atuam no controle das populações de outros insetos. Por outro lado, para muitos animais, a formiga é fonte de alimentação (Lach et al. 2010).

Há de se destacar que as formigas também podem ser intituladas pragas ou pestes, principalmente em razão da dominância em alguns habitats, dos ferrões e do desequilíbrio ambiental. A ideia das formigas como peste é antiga. Carolus Linneaus, pai da taxonomia 
moderna, indicou, equivocadamente, a "formiga faraó", também conhecida como formiga do açúcar, como uma das pragas bíblicas durante o antigo Egito, refletindo este preconceito (Ebeling 11996). Em Macunaíma, o personagem repete o refrão: "muita saúva, pouca saúde, os males do Brasil são" (ANDRADE, p. 117, 2008). Apesar das formigas servirem como referências aos males do Brasil como nessa célebre frase de Mário de Andrade, diversos estudos mostram a inegável importância desse inseto.

\subsection{Os animais nos desenhos de animação}

Atualmente, as crianças vivem grande parte de seu tempo envolvidas com as mídias audiovisuais tais como televisão, celular, tablet, etc. E, como elas são alvo da indústria do consumo, as animações se esmeram no requinte das produções, na técnica, estética, criatividade e sensações que provocam o espectador. Os primeiros desenhos animados do início do século XX tinham como público-alvo as crianças, com o advento da Disney, eles se tornaram parte de toda a infância (VIZACHRI, 2014, p. 57). Atualmente são sucesso de público, inclusive entre os adultos. O rei leão, Irmão Urso, Bambi, Dumbo, Bee Move, Rio, Happy Feet, O cão e a raposa, Kung Fu Panda, Procurando Nemo, Os dálmatas, Madagascar, A era do gelo, entre outros, são exemplos de animações que encantaram e ainda encantam crianças e adultos.

Segundo Lucena Júnior (2001, p.29), a origem da palavra animação advém do verbo latino animare, que significa "dar vida". O desenho animado transforma "corpos, seres, objetos e imagens, fazendo dessa narrativa o espaço da magia e do encantamento, onde o impossível e o irreal adquirem vida, forma e representação" (SALGADO, 2005, p. 49).

Por sua vez, Bortoletto (2008) define o desenho animado como um gênero discursivo de obra ficcional, com mensagens valorizadas a partir das relações estabelecidas em sociedade. Para essa autora, os desenhos animados, como qualquer outra produção cultural, exprimem ideias e, portanto, atuam sobre a realidade, assim como também são afetados por ela.

Em sua investigação, Vizachri (2014) indica que raros são os desenhos animados que não utilizam animais como personagens principais em interação com humanos ou que substituem completamente os próprios humanos. Vizachri (2014) constata, em suas investigações que, nos filmes de animação, a fala é um elemento estruturante da humanização dos animais. Ainda conforme essa autora, quanto mais a sociedade se urbaniza, mais se afasta dos animais e aumenta a representação deles nas telas. Ressalta que os animais antropomorfizados das telas encantam o público porque é próprio dos humanos identificar-se 
com os animais e também estranhá-los. Por isso, temos questões conflitantes no nosso modo de interagir com eles.

A presença incisiva dos animais no cinema de animação se justifica pelas preocupações de ordem ecológica que têm movido a sociedade contemporânea e por uma tomada de consciência dos problemas éticos que envolvem a nossa relação com os animais não-humanos (MACIEL, 2011). De outro modo, pode-se considerar que os desenhos de animação seguem a lógica das representações infantis para dialogar com o universo do imaginário de seus consumidores. Para a indústria de animação, as questões ecológicas servem como um elemento a mais às tramas mais recentes.

Berger (2009), ao dissertar sobre a comparação entre as sociedades humanas e não humanas afirma que os animais são a intercessão entre o homem e suas origens. Destaca esse autor o uso universal de signos animais para mapear a experiência humana do mundo. Berger (1980) salienta que figuras de animais foram o primeiro tema para a pintura, enquanto seu sangue foi provavelmente a primeira tinta utilizadas pelos homens primitivos, levando à necessidade de aproximação física e delineando o possível início de sua relação de exploração, presente até os dias atuais no uso de animais para fins de alimentação, de pesquisas laboratoriais, de matéria-prima e, ainda, de mercadoria da indústria cultural.

Como as imagens dos animais nas animações são compreendidas como produto, elas são construídas de forma a ajustar ao deleite e às necessidades humanas. Dessa maneira, nessas produções fílmicas, a vida dos animais e dos seres humanos têm limites tênues. Cada desenho animado cria maneiras de encontro com a vida animal como um desafio à imaginação. Os animais dos desenhos animados encantam aqueles que a eles assistem, pois geralmente, o trabalho dos animadores consiste em traduzir um comportamento estranho em algo familiar. Assim, as animações deixam sempre um rastro de conhecimento sobre o animal representado tanto escondem os animais quanto os revelam. Portanto, o trabalho de compreensão das imagens dos animais nos filmes de animação revela o (des) conhecimento social sobre eles. Desse modo, compreender as representações dos animais nas animações é uma possibilidade de cotejar a natureza da imaginação com a natureza da vida real que não se apresenta como espetáculo, paraíso ou apenas um cenário. 


\subsection{A multimodalidade nos desenhos de animação}

A grande quantidade de imagens que hoje circulam nos espaços sociais colocou os estudos sobre as linguagens visuais em destaque. Atualmente, as investigações sobre os textos escritos dividem espaço com textos que apresentam duas ou mais modalidades semióticas em sua composição. Para Pimenta e colaboradores (2010), essas mudanças mostram a natureza dinâmica da comunicação na sociedade contemporânea, por meio das quais experimentamos diferentes modos de significar o mundo. Segundo Kress e Van Leeuwen (2006), toda forma de comunicação é multimodal. Para esses autores, no decorrer no século XX, a diversidade dos modos semióticos alterou as formas de comunicação, de modo que é bastante comum a produção de textos multimodais nas diversas práticas comunicativas. Fairclough (1989, p.27), ao investigar os efeitos sociais dos textos, indica a combinação de mais de um modo semiótico nos materiais impressos, fílmicos e televisionados. Para esse autor, os elementos visuais e verbais são interdependentes na maioria das produções, de forma que se torna muito difícil isolá-los. Kress e Van Leeuwen (2006.) defendem que a estrutura visual não é apenas um suporte para as estruturas linguísticas, visto que a primeira também expressa interpretações e formas de interação social.

Para Kress et. al (2001), a teoria multimodal objetiva investigar como os textos visuais e linguísticos constroem a realidade; como recortam o mundo e como intencionalmente podem omitir detalhes. A teoria multimodal se fundamenta na gramática do design visual, apresentada na obra Reading images (KRESS e VAN LEEUWEN, 2006). Esses autores estabelecem, nessa gramática visual, que os significados representacionais, os interacionais e os composicionais operam simultaneamente em toda imagem. As representações da realidade vão além do valor comunicativo, traduzem aspectos estéticos e ideológicos.

No que concerne aos objetivos deste trabalho, a gramática do design visual nos auxilia na reflexão do modo como as imagens são apresentadas e os critérios estéticos utilizados em sua produção. Nas animações, o aspecto visual tem um impacto muito grande sobre o telespectador. Nesse sentido, a utilização dos postulados da gramática visual, que serão vistos nesta investigação, vão evidenciar como as imagens constroem diversos significados nos textos multimodais.

A configuração da animação constitui um elemento de extrema importância para a identificação do público-alvo. Sendo assim, a morfologia das formigas, a vida social, os lugares em que aparecem, as cores dos insetos e outros elementos visuais presentes nesse gênero textual 
funcionam como pistas para que a audiência se identifique com o desenho animado. Essas pistas não podem ser vistas apenas como categorias biológicas, mas como recursos da linguagem cinematográfica que seleciona e recorta os elementos que deseja exibir. Para Vizachri (2014), nos filmes de animação, essa "visão artística" é ampliada em virtude de todos os detalhes excessivamente planejados que o diretor pretende exibir. Conforme Vygotsky (2009, p.37), "a paixão das crianças pelo exagero, do mesmo modo que a dos adultos tem fundamentos internos muito profundos, que, em parte, consiste na influência que o nosso sentimento interno tem sobre impressões externas", ou seja, o interesse nos desenhos animados é geralmente centrado naquilo que é extraordinariamente fora do comum. Além do entretenimento, esse é um dos motivos pelos quais as animações modificam fatos e fenômenos criando proporções de exacerbação.

Concluindo, a criação permite que os animais apresentem vidas tipicamente humanas, que tenham cor e acessórios idealizados pelo diretor, sem, contudo, desprezar alguns aspectos da biologia desses organismos que necessitam ser evidenciados. Nessa perspectiva, este trabalho, ao abordar a representação de formigas em algumas animações, reafirma a ideia da imagem como uma expressão cultural. Assim sendo, apesar da percepção objetiva, as formigas dos desenhos aqui tratados, são mais do que aparentam ser.

\section{METODOLOGIA}

Neste estudo, cujo propósito é investigar a representação de formigas nas animações, o primeiro procedimento que guiou essa investigação envolveu a busca intensa por desenhos animados tendo as formigas como protagonistas. Variadas animações foram encontradas em plataformas de transmissão on line como Netflix e Youtube. Para análise dos materiais, foram selecionadas as animações mais citadas em portais de notícias e entretenimento priorizando aquelas popularizadas nos cinemas e televisão. Desse modo, as animações com maior recorrência de citações envolvendo a vida das formigas foram: A Formiga atômica, Formiguinhaz, Vida de inseto, Lucas: um estranho no formigueiro e Minúsculos: o vale das formigas.

Para compreender como as formigas são significadas nos desenhos foi preciso assistir a cada desenho mais de uma vez, fazendo anotações do que era recorrente e, ao mesmo tempo, singular na representação das formigas. Inicialmente, as primeiras categorias foram inspiradas no "Guia para os gêneros de formigas no Brasil" (Baccaro et. al, 2015). Nesse livro, verificouse a importância de destacar a morfologia, a vida social, o ciclo de vida, a alimentação, o 
habitat, a interação com outros organismos, o comportamento e o polimorfismo desses insetos. Nesse processo, as questões relacionadas às características mais visíveis foram preponderantes. Contudo, as reiteradas análises do material empírico indicaram a relevância de incluir, também, o antropoformismo, haja vista que essa categoria é muito expressiva nos desenhos e elementos da gramática visual, tais como as cores das formigas, o comportamento, os ambientes em que aparecem, as relações de poder manifestadas nas representações. Desse modo, as categorias que serviram de referência para análise, podem ser observadas no quadro abaixo:

\begin{tabular}{|c|c|}
\hline Categorias & Características \\
\hline 1. Ciclo de vida & Transformações dos indivíduos ao longo da vida \\
\hline 2. Vida social & $\begin{array}{l}\text { Formigas em grupo, em fila, no formigueiro, divisão do } \\
\text { trabalho e comunicação entre elas }\end{array}$ \\
\hline 3. Habitat & $\begin{array}{l}\text { Formigas na grama, no chão, na árvore, na parede, no } \\
\text { formigueiro, etc }\end{array}$ \\
\hline 4. Antropomorfismo & Aspectos físicos e comportamentos humanos. \\
\hline 5. Interação & Relação das formigas com outros organismos. \\
\hline 6. Morfologia & $\begin{array}{l}\text { Corpo dividido em } 3 \text { partes, cabeça, tórax e abdômem; } \\
3 \text { pares de pernas e } 1 \text { par de antenas; } 1 \text { par de olhos } \\
\text { compostos e } 1 \text { par de mandíbulas. }\end{array}$ \\
\hline 7. Polimorfismo & Diversidade de cor, forma e tamanhos. \\
\hline 8. Alimentação & $\begin{array}{l}\text { Frutas, açúcar, carapaças de insetos, restos de alimentos } \\
\text { humanos, néctar, seiva de plantas, etc }\end{array}$ \\
\hline 9. Comportamento & $\begin{array}{l}\text { Divisão em castas, sexo dos indivíduos nas castas, } \\
\text { divisão de trabalho entre castas, etc. }\end{array}$ \\
\hline
\end{tabular}

De modo a dar maior confiabilidade ao processo de interpretação das imagens, os pesquisadores deste trabalho analisaram as animações colaborativamente, para reduzir as distorções de interpretações provenientes de um único investigador, conforme recomendações metodológicas de Bogdan e Biklen, 1994. Assim, o tópico seguinte apresenta a análise de cada animação aqui estudada. 


\section{ANÁLISE E RESULTADOS}

Ao longo da história das animações infantis, as formigas foram apresentadas como protagonistas em pelo menos cinco desenhos, entre os quais destacam-se: A Formiga atômica, Formiguinhaz, Vida de inseto, Lucas: um estranho no formigueiro e Minúsculos: o vale das formigas. Além desse protagonismo, essas animações foram selecionadas para a investigação porque se destacam pelo recorde de público.

\subsection{A Formiga Atômica}

A Formiga atômica é uma criação dos estúdios Hanna-Barbera. A primeira série conta com 26 episódios com aproximadamente 6 minutos de duração. Ela foi lançada nos Estados Unidos em 1965. No Brasil, a animação foi apresentada na extinta TV Tupi nos anos de 1970. Posteriormente, nos anos de 1980 e em outras décadas foi exibida em outras emissoras.

A Formiga atômica é uma versão em miniatura dos super-heróis. Os episódios são marcados pelo altruísmo do personagem que parece mais preocupado em ajudar o próximo do que receber algo em troca pelos serviços prestados. Além do entretenimento, a série busca ensinar às crianças valores como: coragem, responsabilidade, destemor. A formiga é retratada com dois braços, duas pernas, roupas, uso de computadores, alteres, motos, capacetes, pensamento racional e com superpoderes. Ela não tem maxilares e seus olhos têm íris e são redondos. Mesmo sem asas, ela "voa" com muita velocidade e é capaz de levantar quase cerca de 50 vezes o seu próprio peso. Além do tamanho e do par de antenas, a força talvez seja o único traço que aproxima a animação da realidade. É importante observar que as formigas só conseguem carregar objetos muito pequenos e mais pesados que seu próprio peso porque a estrutura de seu esqueleto, a presença de seis pernas e sua musculatura permitem essa proeza, o que não é o caso da protagonista dessa animação.

As antenas da Formiga atômica funcionam como uma espécie de radiocomunicador. $\mathrm{Na}$ série animada, o formigueiro é uma estrutura sinuosa, sem galerias, que culmina em uma cavidade em que a Formiga atômica vive solitariamente. Na série, não há referência ao ciclo de vida das formigas.

Nos desenhos da série, não há informação ecológica ou biológica referente ao ambiente das formigas. Na animação, a formiga é sempre muito requisitada pela polícia no combate ao crime. Ela mora em um formigueiro que é seu esconderijo onde possui um laboratório com um 
supercomputador e, ainda uma pequena academia com sofisticados equipamentos de musculação, uma estratégia dos autores para justificar sua força.

Nota-se nessa série que a formiga não é representada como um animal nocivo, mas no episódio "Formigas selvagens", ela combate as "formigas do mau". As formigas selvagens invadem uma área de piquenique. Uma referência claramente negativa ao conceito de selvagem, retratando o contato de pessoas que se sentam em um gramado e são perturbadas por formigas que são atraídas pela comida. Além disso, uma referência à interação negativa dos americanos, que cultuam casas com enormes gramados, onde aparece uma espécie de formiga invasora do gênero Solenopsis "fire ants", considerada pragas urbanas nos EUA. No episódio denominado "Formigas selvagens", uma única formiga come um bolo inteiro. Aliás, a presença das formigas no parque é associada à presença de alimentos doces. As formigas selvagens são retratadas nesse desenho como animais que devoram alimentos doces que roubam restos de comida.

Embora outras formigas apareçam na animação, com exceção das roupas, suas características morfológicas são idênticas às da Formiga atômica.

Nesse episódio, as formigas são retratadas no "velho oeste" americano. Elas são caracterizadas como seres humanos. Assumem a posição bípede, têm olhar, mãos e pés humanos e mantêm relações típicas das sociedades humanas, tanto intraespecificamente quanto com outras espécies. As formigas selvagens são representadas como os povos indígenas norteamericanos. Portanto, as concepções culturais dos norte-americanos e seus preconceitos são "subliminarmente" incluídos na mensagem da animação.

\subsection{Formiguinhaz}

Formiguinhaz é uma criação dos estúdios Dreamworks. O filme infantil tem 87 minutos de duração, foi lançado nos cinemas em 1998. “Z”, protagonista da história, é uma formiga operária que questiona a posição que ocupa na sociedade. $\mathrm{O}$ formigueiro é apresentado como uma sociedade na qual a opressão está em todos os cantos. Em companhia da princesa Bala, "Z" parte em busca da "Insetopia", um lugar de liberdade e comida abundante. O general Mandíbula, vilão da história, é uma “formiga militar”, rígida, rude e intolerante com as formigas operárias. Ele se ocupa apenas das questões de guerra e da construção de um "Mega Túnel" que pode inundar o formigueiro e matar todas as formiguinhas "fracas" e construir uma "colônia forte", de guerreiros. Mas, "Z" consegue salvar a colônia e se casar com a princesa Bala. Formiguinhaz ainda hoje é uma animação utilizada por muitos professores para discutir a luta 
de classes. Uma das lições que ela busca ensinar é a importância do trabalho em grupo, a iniciativa a reflexão e o diálogo.

"Z" é retratado com o corpo segmentado ou dividido em três partes, um par de antenas, quatro pernas e dois braços. As antenas dos indivíduos dessa animação têm uma função meramente estética. Em "Formiguinhaz", os insetos são caracterizados como seres humanos. Eles são bípedes e mantêm com o tórax ereto. Em relação à diversidade de cor, forma e tamanho, machos e fêmeas de uma mesma casta apresentam aspectos morfológicos semelhantes, embora algumas fêmeas apresentem antenas circulares que não são comuns às espécies. A distinção de indivíduos de castas diferentes se dá pelo tamanho, forma do rosto e corpo que indiciam a separação em classes: soldados fortes e operários magros com capacetes. As formigas são representadas com feições humanas, dentes humanos, mas com o resto do corpo "próximo" à morfologia de uma formiga. Elas são apresentadas com olhos grandes, íris e pálpebras. Na animação todos os soldados são machos.

A atribuição de valores humanos às formigas é um traço marcante desta animação dado ao propósito de discutir questões sociais como dominação, individualismo e liberdade em uma sociedade em que todos têm papéis definidos. As operárias escavam túneis e transportam pedras e alimentos no dorso; os soldados combatem os cupins e algumas fêmeas aparecem cuidando das larvas da colônia. As formigas são retratadas dentro e fora da colônia, que é apresentada com uma estrutura colossal iluminada, remetendo às grandes cidades.

A rotina da colônia é exibida como um lugar de trabalho nas suas infinitas galerias. Dentro dela tudo é estabelecido conforme uma ordem proveniente do poder da rainha. A organização do tempo e divisão de tarefas é outro traço desta animação. Em relação à reprodução desses indivíduos, aparece em uma das cenas, algumas operárias levando à rainha, larvas para que determine quem será operária, no caso dos indivíduos mais fracos, ou será militar, caso dos mais robustos - regulando assim a vida da colônia. Embora o objetivo não seja apresentar o ciclo de vida das formigas fica subtendido que esses insetos sofrem metamorfose haja vista que as larvas são muito diferentes dos insetos adultos.

Em Formiguinhaz, os indivíduos machos vivem no formigueiro e apenas um deles é representado com asas. A rainha aparece próxima às larvas com um abdômen volumoso indiciando que a reprodução é uma tarefa exclusiva da rainha. Além do tamanho do abdômen, ela se destaca pela coroa e pela superioridade em relação às outras formigas; é ela quem regula o trabalho e as ações no formigueiro. Apesar do poder atribuído à rainha, o general mandíbula 
exerce forte influência nas ações dela. O que a diferencia dos outros indivíduos são, principalmente, as antenas e o tamanho do abdômen.

Em uma das cenas, as formigas se alimentam de uma substância expelida pelos pulgões em uma relação de exploração pois, apenas as formigas se beneficiam na interação. Na natureza, os pulgões secretam um líquido adocicado que é ingerido por algumas espécies de formigas, que, por sua vez, protegem-no dos seus inimigos caracterizando essa interação como mutualismo.

As formigas não são apresentadas como animais nocivos. Na animação, os inimigos são o general Mandíbula, os cupins e um louva-deus. As formigas usam sua supremacia numérica para combater esses inimigos. O louva-deus, que, no desenho, parece ser um predador das formigas, um "inseto mau”, possui características morfológicas mais próximas a um inseto real, com olhos compostos, dois pares de asas e palpos maxilares e labiais grandes e bem destacados.

\subsection{Vida de inseto}

O filme Vida de Inseto foi lançado em 1998 no Brasil pela Pixar. A película nos conta a história de Flik, uma formiga macho inventora que não consegue se ajustar às regras de seu formigueiro. $\mathrm{Na}$ animação, a Princesa Atta é treinada pela avó para tornar-se rainha. Após a colheita, as formigas são obrigadas a entregar parte da produção a um grupo de gafanhotos. Na tentativa de melhorar o transporte dos grãos que seriam entregues como "oferenda" aos gafanhotos, Flik inventa um mecanismo que não funciona e desastrosamente leva à perda dos grãos, ameaçando a existência da colônia. Por causa disso, Flik é banido do formigueiro, mas encontra um grupo de insetos circenses que ele acredita que são capazes de libertar o formigueiro da tirania dos gafanhotos. Ao final, o formigueiro é libertado dos gafanhotos por uma invenção de Flik que passa a ser visto como herói. A importância do trabalho coletivo e da criatividade, a obstinação e a coragem são ensinamentos que esta animação busca mostrar às crianças.

Quanto às características morfológicas, as formigas são retratadas com o corpo segmentado em três partes, um par de antenas e duas pernas e dois braços, e uma delas surgindo do abdômen. Elas não são apresentadas como animais nocivos. Nenhum indivíduo tem mandíbulas. Nota-se que as antenas das rainhas diferem das antenas dos outros indivíduos que apresentam antenas arqueadas. 
As formigas caminham como bípedes e têm mãos. As antenas dos indivíduos dessa animação têm função decorativa. As formigas têm a mesma cor, uma cor roxa, forma e tamanho. Observamos que machos e fêmeas apresentam aspectos morfológicos semelhantes, a diferença entre eles são os adereços, a estrutura das antenas e expressões faciais e formato da cabeça. Contudo, indivíduos de diferentes gerações e as rainhas são retratados com aspectos diferentes indicando que a hierarquia e o poder na colônia estão ligados à idade.

Os personagens apresentam comportamentos humanos. A imaginação, a criatividade, a amizade e a solidariedade são elementos explorados no desenho. Com efeito, a atribuição de valores humanos às formigas é um traço marcante desta animação dado ao propósito de discutir questões sociais como dominação, união e liberdade. As formigas carregam grãos e frutos com as mãos, acima da cabeça. Elas são retratadas dentro e fora da colônia que é apresentada como um lugar onde as formigas vivem e guardam a sua comida. Não há divisão de câmaras no formigueiro nesta animação.

Em relação à reprodução desses indivíduos, embora haja referência à fase larval, observa-se que o ciclo de vida das formigas não é apresentado. Aliás, ovos e larvas não aparecem na animação. São apresentados insetos adultos e crianças em analogia à vida humana. Nota-se no desenho que os indivíduos machos vivem no formigueiro e apenas um indivíduo macho é representado com asas. Durante o filme, três gerações de rainhas são apresentadas. Elas têm asas e sua morfologia se assemelha a outros indivíduos da colônia. A coroa, a idade e o poder explícito da rainha-mãe é que a diferencia das outras duas. Ela apresenta músculos faciais flácidos que se assemelham a uma pessoa idosa. A rainha mais velha cuida de um "pulgão" que representa um cachorro na animação. Ela se destaca pela idade, coroa e pela superioridade monárquica. Em relação às outras formigas, é ela quem regula o trabalho e as ações no formigueiro.

As formigas são apresentadas carregando grãos e frutos, mas não aparecem se alimentando. A interação com outras espécies ocorre como amizade ou exploração. Os gafanhotos são apresentados como "inimigos" das formigas, contudo trata-se de uma informação distorcida da realidade porque as formigas é que são predadoras desses insetos. Os animais "amigos" das formigas aparecem mais humanizados, enquanto os inimigos ou predadores apresentam características morfológicas mais próximas aos insetos reais. 


\subsection{Lucas: um intruso no formigueiro}

Lucas: um intruso no formigueiro é um filme da Warner Bross de 2006. Lucas é uma criança que, intimidada por um menino, descarrega sua raiva no formigueiro do gramado de seu jardim. O bullyng que Lucas sofre motiva-o a agir de forma cruel na colônia. Para vingarse, uma formiga com conhecimentos em alquimia, prepara um elixir para Lucas diminuir de tamanho. Então, as formigas levam-no até o formigueiro para que ele seja julgado pelos estragos da colônia. A rainha decide que Lucas deverá viver como uma formiga para aprender como é a vida na colônia. Reduzido ao tamanho das formigas, Lucas aprende o valor do coletivo mediante a cooperação e a divisão do trabalho. Aprende também que o jardim familiar é um campo de batalha territorial repleto de dramas de vida e de morte. Decorrem desse enredo as lições que a animação procura ensinar às crianças: o trabalho colaborativo, o valor da amizade e da coragem.

O desenho mostra os túneis subterrâneos e câmaras secretas de uma agitada colônia de formigas de um jardim. Nas primeiras cenas, elas aparecem pequenas e indistintas.

No desenrolar da história, observa-se marcas que distinguem os indivíduos, aspectos humanos, rostos individuais e expressivos. $\mathrm{O}$ abdômen dos indivíduos machos se difere do das fêmeas pelo tamanho e forma. As formigas são representadas com o corpo segmentado em três partes e três pares de patas sendo que as pernas médias são mais próximas das posteriores. Em uma das cenas, uma formiga indica corretamente que o seu coração fica no abdômen. Os machos vivem no formigueiro e suas relações são típicas das sociedades humanas. Eles apresentam um dente externo que lembra as mandíbulas de uma formiga. As formigas são mostradas caminhando em diferentes planos. As antenas movimentam-se de acordo com as emoções dos personagens. Os olhos das formigas são humanizados, mas apresentam retículos que lembram o olho composto ou facetado dos insetos.

Os soldados são apenas do sexo masculino. As formigas aparecem trabalhando dentro e fora do formigueiro. A importância da coleta pelas formigas é indiciada em uma das cenas em que as formigas mais jovens são treinadas para esse trabalho. Os indivíduos da colônia são vistos coletando sementes, folhas e frutas e se alimentam de uma substância expelida por pulgões. Também nesta animação, a interação entre as formigas e os pulgões não é explorada. Os pulgões aparecem como animais que fornecem alimento gratuito às formigas.

Na colônia há a divisão do trabalho, mas as castas não são corretamente explicitadas e definidas. A rainha é representada como um ser divino, olhos não humanizados, maior que os 
outros indivíduos, sem mandíbulas, com apenas um par de asas. Na colônia, o comportamento das formigas é determinado pela rainha.

Também nessa animação as formigas apresentam comportamentos humanos. Observase em uma cena a tentativa de extermínio do formigueiro pelos humanos. Em outra cena aparece um personagem tentando matar uma formiga que passeia pelo biscoito por considerá-la nociva.

A fundação da colônia é atribuída à rainha. Ela é vista como uma espécie de deusa e indica que todas as formigas são descendentes dela, todas são chamadas por ela de filhos. De seus ovos nascem formigas para diferentes funções. O ninho se apresenta como um emaranhado de túneis e câmaras com funções específicas e túneis que as interligam. No aposento real, há câmaras de ninhada, de lixo, de armazenamento de alimentos. As formigas se mostram religiosas tal como os seres humanos.

A câmara de chocagem dentro do formigueiro é subterrânea. Algumas formigas cuidam dos ovos, larvas e pupas. Nesse estágio, elas são representadas com uma pele esbranquiçada e ficam no colo de algumas formigas lembrando os bebês humanos.

Os inimigos das formigas são os humanos, gafanhotos e as vespas. As vespas e os gafanhotos aparecem no filme atacando a colônia. Também nesta animação, os insetos, inimigos da colônia apresentam traços morfológicos mais próximos à realidade, como olhos compostos diferentes dos olhos humanos, dois pares de asas e mandíbulas. Os gafanhotos também aparecem como inimigos das formigas.

\subsection{Minúsculos: o vale das formigas perdidas}

"Minúsculo - o vale das formigas perdidas" (2013) é uma animação de uma hora e meia que retrata a jornada épica de uma joaninha que participa de uma guerra travada entre colônias rivais de formigas disputando torrões de açúcar que restaram de um piquenique. $\mathrm{O}$ filme foi inspirado na série "Minúsculos - a vida privada dos insetos" (2006). Não há diálogos no filme. Interessante nessa animação é a técnica de inserir as formigas em computação gráfica num cenário real, uma floresta francesa. Questões universais como amizade, solidariedade, tolerância e convivência pacífica são a tônica do filme.

Na primeira cena vê-se um gramado, visto de longe, sem movimento, mas olhando de perto, há muita movimentação, provocada por formigas pequenas e indistintas. Estão caminhando em fila, coletando folhas, sementes e frutas. A imagem das formigas também nesta animação, é associada ao trabalho. Diferentemente das outras animações em que os alimentos 
são carregados nas costas, em Minúsculos, os alimentos são presos na mandíbula como as formigas do mundo real.

A representação morfológica das formigas que aparecem neste desenho se aproxima à realidade: dividida em três segmentos, três pares de pernas, mandíbulas e duas antenas. As pernas saem do tórax e as antenas são representadas formando um cotovelo (tecnicamente chamada de antenas geniculadas), aspectos que caracterizam a espécie. Os olhos não retratam os olhos compostos dos insetos. O filme mostra formigas pretas e vermelhas. Neste caso, a diversidade entre as espécies é marcada pela cor e pelo formato do rosto das formigas. As formigas vermelhas, vilãs da história, são retratadas como animais nocivos, com feições rudes, as características físicas são semelhantes às formigas pretas.

Contudo, todas as formigas são retratadas como insetos que vivem e trabalham em equipe. Elas são representadas com a inteligência de humanos, com memória e pensamento abstrato. $\mathrm{Na}$ animação, elas utilizam aparelhos, fósforos, foguetes, e outros equipamentos. Fazem uso de técnicas de guerra, cercam os inimigos e protegem o formigueiro usando estratégias humanas. Elas comunicam entre si e com as joaninhas por sinais sonoros similares, quando, no mundo dos insetos, a comunicação é preponderantemente química.

A divisão de trabalho na colônia, o ciclo de vida e a variação da estrutura social do formigueiro são elementos pouco explorados na animação. Os inimigos das formigas, como por exemplo, um lagarto verde que surge no desenho é retratado de maneira realista.

Quanto à interação com outros insetos, é destacada principalmente na amizade que se estabelece entre a joaninha e uma das formigas que comunica com o grupo por meio de assovios e as antenas. Segundo Barnes et al (2005: 858), Gallo et al (2002: 163-164), Lara (1992: 134139) e Michael (1999: 15) as antenas exercem funções sensoriais podendo envolver os mais variados sentidos incluindo tato, olfato e paladar. O tato é bastante aguçado em virtude de a antena possuir filamentos nervosos que possibilitam à formiga destacar essa sensação. Mas também o corpo, que possui pelos em toda sua extensão, pode estimular - transmitir sensação tátil.

Nota-se no filme que elas se alimentam e protegem umas às outras. Frutas e açúcar são os alimentos preferidos das formigas. E, são por causa dos torrões de açúcar que as colônias entram em guerra. $\mathrm{O}$ formigueiro é subterrâneo e um monte de terra indica a entrada do formigueiro. O emaranhado de túneis é apresentado embora apenas as funções da câmara da rainha e da câmara em que os ovos são depositados sejam explicitadas. 
O filme retrata o interior da colônia como algo vivo e organizado. No formigueiro, não há distinção de sexo das formigas indicando machos e fêmeas. Assim, com exceção da rainha, nenhuma formiga é representada com asas. Duas rainhas aparecem no filme: uma pertencente à colônia das formigas pretas e outra, da colônia das formigas vermelhas. As duas rainhas são representadas ocupando um papel de superioridade em relação aos outros indivíduos. As duas atuam como reguladoras da colônia. São as únicas fêmeas aladas da colônia. Todos os alimentos do formigueiro são inspecionados pelas rainhas cuja alimentação é diferenciada do resto do formigueiro.

As rainhas são bem maiores que os outros indivíduos e, o tamanho do abdômen delas dificultam a locomoção. O filme retrata uma das rainhas colocando uma quantidade enorme de ovos de uma só vez. A rainha das formigas pretas vive em companhia de alguns pulgões, mas a associação entre eles não é mostrada.

\section{Formigas na escola: implicações deste estudo para o ensino de ciências}

Quanto mais as discussões ecológicas se popularizam, mais a indústria cultural explora temas relacionados à natureza apresentando animações envolvendo a representação de animais. Assim sendo, as animações, além de produtos destinados ao entretenimento, atualmente podem ser utilizadas na esfera educacional.

Com efeito, em uma investigação sobre a representação de formigas pelas crianças no ambiente escolar, Rodrigues (2017) analisa o registro de uma das crianças investigadas sobre o seu desenho de uma cena do filme "Homem Formiga" quando convidada a expressar seus conhecimentos sobre as formigas. Eis o desenho do aluno:

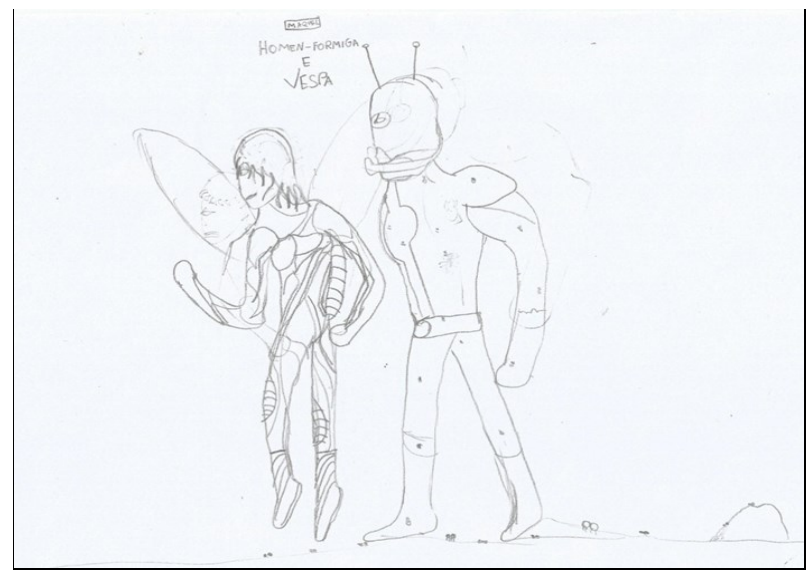

Figura 1: Desenho do aluno Geraldo 10 anos Fonte: Rodrigues 2017. 
Como se vê na figura acima, o desenho de Geraldo remete aos personagens principais do filme "Homem Formiga". A história desse filme mostra o protagonista interagindo com as formigas, a sua descoberta do uso de substâncias químicas secretadas pelas formigas para se comunicarem com as outras de sua espécie. O filme exibe uma cena em que, após meses de trabalho, o protagonista cria um "capacete cibernético", o qual lhe permitiria se comunicar com formigas por meio da transmissão e recepção de ondas feromonais/elétricas. Com esse capacete, ele conseguiu controlar inúmeras formigas que iriam ajudá-lo em suas aventuras. Assim, Geraldo se inspira nessa produção para fazer o desenho de uma formiga. O homem-formiga retratado por ele tem um capacete, possui antenas e usa roupa especial. No seu corpo foram desenhadas formigas minúsculas o que remete ao controle desses insetos pelo personagem do filme. As formigas foram desenhadas em grupo. O habitat da formiga foi representado, no canto da folha. Quanto à morfologia da formiga não está claramente visível, dado o tamanho do desenho. $\mathrm{O}$ foco do registro recai no herói e no vilão do filme. A representação desse aluno, ocorreu antes de uma intervenção escolar sobre as formigas, o que já evidencia o importante papel da mídia no processo de aprendizagem das crianças.

Em seu trabalho, Rodrigues (2017) também apresenta outro registro do aluno Geraldo produzido após ter assistido ao desenho Minúsculos. Acerca dessa animação, ele apresentou o seguinte desenho:

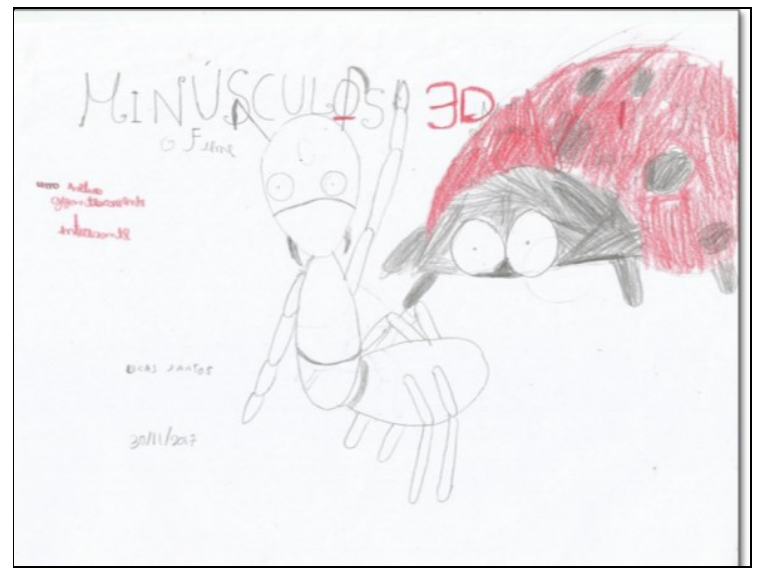

Figura 2: Desenho do aluno Geraldo - 10 anos Fonte: Rodrigues (2017).

Nota-se mais uma vez no desenho desse aluno que ele procura retratar os protagonistas da produção, neste caso, a formiga e a joaninha. Observa-se que procurou realçar os detalhes da formiga. O corpo dela é segmentado em três partes, possui seis apêndices locomotores, duas antenas e mandíbulas. As partes do corpo da formiga são ovaladas. Ele desenhou as patas 
distribuídas ao longo do corpo do animal, com alguns detalhes da articulação demonstrando sua observação apurada da animação. Os olhos são redondos, mas não remetem a olhos humanos.

O estudo de Rodrigues (2017) mostra que a representação das formigas foi modificada pela maioria das crianças após terem assistido aos desenhos revelando o quão importante foi a exibição e a mediação da professora no trabalho com as animações. Os desenhos animados mobilizam as crianças, fazem parte do universo delas. Elas conhecem todos os personagens, suas falas, algumas conhecem até detalhes da produção dos desenhos. Portanto, um dos objetivos deste estudo é mostrar que as animações oferecem elementos que podem servir como estratégia para o ensino de ciências. O presente estudo apresenta, diferentes representações de formigas presentes nas animações que podem ser trabalhadas em sala de aula. As professoras podem levar as crianças a comparar diferentes concepções de formigas e a desenvolver um olhar mais aguçado para os animais, para além do prazer que as animações lhes proporcionam. Afinal, a observação é uma "atividade científica que implica olhar objetos, fatos e fenômenos com "lentes" específicas que permitem relacionar diferentes fatores observados em um marco de conhecimentos, ideias e questões" (PUJOL, 2007). Assim, assistir com as crianças aos desenhos animados e conversar com elas sobre essas representações é ensinar-lhes a "olhar o mundo", conhecer um pouco sobre "o mundo dos insetos". Outro objetivo desta investigação é conscientizar as professoras acerca do potencial das animações infantis para o ensino de ciências. A educação do olhar é necessária e constante para crianças e adultos. Para tanto, tornase necessário que as professoras conheçam os desenhos e que reconheçam neles aspectos importantes para chamar a atenção das crianças. É importante que elas acreditem que muitos conteúdos biológicos podem ser aprendidos a partir da observação de pequenos insetos como as formigas, para além das questões culturais presentes nos desenhos. Enfim, assistir às animações com as crianças e conversar com elas sobre as representações neste caso, das formigas presentes nos desenhos pode ser um grande passo para a aprendizagem desse grupo de animais. Assim, para que as crianças adquiram conhecimento, no caso em pauta, das formigas, é necessário que reconheçam as características que definem esse grupo, que encontrem vestígios delas, que persigam rastros de seus pés que caminham em trilhas, que descortinem a movimentada vida das formigas, de organização (in) visível a olho nu. 


\section{CONSIDERAÇÕES}

Ao construir um filme sobre formigas, seus criadores trazem para a tela erros e acertos sobre a morfologia e a biologia desses organismos. Como produções culturais construídas em um grupo imerso na sociedade, carregam marcas do imaginário coletivo sobre o significado das formigas. $\mathrm{O}$ aspecto mais significativo desse imaginário coletivo é tentar ver, na organização da sociedade das formigas um modelo a ser empregado nas sociedades humanas. Nesse sentido, as animações apresentam, como questão central, valores morais, dentre os quais se destacam: o altruísmo, a coragem, a obstinação, a criatividade, a solidariedade, a organização hierárquica e o trabalho colaborativo em benefício do coletivo. Esse último aparece notadamente nas animações aqui estudadas: Vida de inseto e as mais recentes como Formiguinhaz, Lucas: um intruso no formigueiro e Minúsculos.

Quanto às características mais comumente usadas nas animações analisadas, para representar as formigas foram as antenas, a vida social, a segmentação corporal e a presença de apêndices ou pernas articulados, características essas comuns a outros insetos. Apesar de apontadas essas estruturas serem citadas, nem sempre elas correspondem à realidade. Observase, por exemplo, que algumas animações apresentam os insetos com duas pernas, mas as formigas possuem três pares de pernas articuladas. As pernas também não aparecem distribuídas por todo o corpo e as antenas não se assemelham às antenas dos insetos reais. Nas animações e nos desenhos, encontram-se traços de características morfológicas e de comportamentos que se assemelham aos dos seres humanos. Nesse sentido, verificou-se que a humanização dos animais é uma estratégia muito presente nas animações. Contudo, essa antropomorfização das formigas apresenta variações. As animações selecionam traços físicos do corpo dos insetos e os associam a comportamentais humanos como referência para suas projeções. Por exemplo, as formigas das animações aqui estudadas, apresentam fortes traços de uma cultura humana ocidental. Assim, em alguns desenhos, as formigas são representadas como pessoas que constituem família, ou seja: pai, mãe e filhos.

Por outro lado, o corpus analisado mostra que as representações mais recentes de formigas se mostraram mais fidedignas em relação à morfologia dos insetos. Isso pode ter ocorrido em virtude do desenvolvimento da tecnologia computadorizada; do conhecimento das formigas que tornaram sua retratação mais próxima à realidade e como uma exigência da sociedade que tem se voltado para as discussões ambientais. Com efeito, comparando-se o desenho da Formiga atômica feito antes do final da década de sessenta, ou seja, antes da 
preocupação com o meio ambiente se tornar uma questão mundial, com a revolução verde nos anos setenta, percebe-se um abismo de diferenças entre as formigas apresentadas nos desenhos. Cabe, aqui, a questão: o que a Formiga atômica tem de formiga além do tamanho e da força? O fato de ser apresentada com apenas dois aspectos que caracterizam uma formiga faz com que ela seja uma formiga no sentido figurado. Já em Minúsculos, não seria possível manter a mesma narrativa se os animais não fossem formigas. Nessa animação, além das outras características físicas próprias desse inseto, elas aparecem andando sobre as seis pernas, com movimentos de formiga, em oposição ao andar ereto bípede mais próximo ao dos humanos. Também em Lucas, em Vida de inseto e em Formiguinhaz, embora antropomorfizadas, as formigas ainda representam aspectos próprios da vida das formigas.

Interessante notar que em Formiguinhaz, as formigas desprovidas de valores humanos são as vilãs. A imagem dos insetos inimigos das formigas, geralmente, é explorada mostrando os animais em tamanho ampliado, sugerindo ameaça. Predadores são sempre associados aos vilões! Assim os animais "maus” apresentam traços morfológicos mais próximos aos insetos verdadeiros, portanto, mais distante dos humanos e, sob certo ponto de vista, são também mais feios e rudes. De modo geral, nas animações, a natureza é perversa, os predadores são maus. Os mais engraçados são gordos e desajeitados; as fêmeas submissas, sem falar no ideal comum de uma sociedade cooperativa e tolerante. Aliás, em todas as animações investigadas "animais bonzinhos" são morfologicamente representados com características físicas e comportamentais humanas. $\mathrm{O}$ fato de as formigas serem, em sua maioria, carnívoras e se alimentarem de outros animais invertebrados vivos ou mortos, também não é destacado nas representações.

Em relação ao ciclo de vida dos insetos observa-se que as animações o apresentam como fases estanques, sem destaque para a metamorfose e a reprodução.

As formigas, tal como nas fábulas são destacadas pelo trabalho, pela disciplina e organização. A vida social delas se resume à convivência em grupo. A organização, a cooperação e a divisão em castas não é explicada, embora haja referências a esses aspectos nas animações. As formigas são retratadas como pequenos titãs e nobres moradores da terra que carregam comida nas costas para sobreviver. Apenas em Minúsculos as formigas aparecem carregando seu alimento pelas mandíbulas. Folhas, frutos e açúcar constituem fonte de alimentação das formigas e não há referência ao armazenamento de folhas nas colônias.

Observa-se, ainda, que as formigas são ambientadas apenas nos jardins, florestas e formigueiros. Com exceção da Formiga atômica, o sistema de colônias é representado por todas as animações. Em Lucas: um intruso no formigueiro, a colônia é apresentada como um lugar 
de trabalho coletivo, de cooperação, com tarefas realizadas por indivíduos diferentes. Em compensação, a divisão em castas deixa dúvidas em relação ao papel das formigas-rainhas, dos machos, operárias e soldados. Em Formiguinhaz, Lucas, Vida de inseto e Minúsculos, a rainha é uma fonte de liderança explícita, contrariando a realidade das colônias. Em Lucas: um intruso no formigueiro, Vida de inseto e em Minúsculos, as rainhas são representadas com asas por toda a vida.

O voo nupcial e a morte do macho também não são aspectos explorados pelos desenhos. $\mathrm{Na}$ vida real, geralmente, machos são produzidos e encontrados nos ninhos por um curto período de tempo. Contudo, em Formiguinhaz e em Lucas, os machos têm papel de liderança e as fêmeas ficam presas a vários tipos de submissão. Em uma das cenas de Lucas, uma fêmea cuida da câmara de ninhada, característica tida como natural ao feminino.

Concluindo, os dados indicam que, de maneira geral, as formigas não estão associadas a animais nocivos ou pragas, mas também não são mostradas como organismos que apresentam um papel ecológico importante. A importância delas para o solo não é explorada e nas interações ecológicas entre as formigas e outros animais do ambiente não são apresentadas. Apenas o líquido expelido (honeydew) pelos pulgões, açúcar e frutas aparece nas animações e nos desenhos infantis.

Ademais, as animações destacam as características e comportamentos humanos como base de suas inferências. Desse modo, os insetos presentes nas animações "desaparecem" nas narrativas cinematográficas e televisivas porque instauram uma narrativa cujo foco é a humanização dos animais. Contudo, é importante destacar que é inerente ao processo de criação que as formigas das animações sejam parecidas com os seres humanos. As formigas das animações não se valem de todas as explicações científicas porque estão no contexto da arte do entretenimento. Só o fato de falarem já as distanciam da sua condição natural. Contudo, é desejável e bastante possível que elas sejam retratadas mais próximas à realidade, como por exemplo, apresentando antenas, três pares de apêndices locomotores articulados, corpo dividido em cabeça, tórax e abdômen, divisão em castas e de trabalho, operárias e soldados sendo do sexo feminino, etc, porque nenhuma dessas características impede ou dificulta tecnicamente a comunicação do enredo pretendido pelo autor com o seu público.

\section{REFERÊNCIAS}

ANDRADE, Mário. Macunaíma, o herói sem nenhum caráter. Rio de Janeiro: Agir, 2008. 
BACCARO, F. B.; et. al. 2015. Guia para os gêneros de formigas do Brasil. Editora INPA, Manaus. 388p.

BERGER, J. Why look at animals? London, Penguin Books, 2009.

BERGER, J. About Looking. London: Writers and Reader Publishing Cooperative,1980.

BOLTON B, 2020. An online catalog of the ants of the world. URL https://antcat.org (Acessado em 18 de agosto de 2020).

BORTOLETTO, M. Ideologias animadas: a criança e o desenho animado. Dissertação Programa de Pós-Graduação em Educação da Universidade Estadual de Campinas, 2008.

EBELING, W. 1996. Pests Ono r Near Food, In: Urban Entomolgy. UC Riverside. University of California (Division of Agricultural Sciences).

FAIRCLOUGH, N. Language and power. London: Longman, 1989.

GULLAN, P. J. \& CRASTON, P. S. The Insects: an outline of Entomology. Chapman \&Hall, 1994. $491 \mathrm{p}$.

HÖLLDOBLER, B \& WILSON, E.O. 2009. The super-organism. The beauty, Elegance, and strangeness of insect societies. W.W. Norton \& Company, Inc. 500 Fifth Avenue, New York, N.Y. 522p.

LUCENA JÚNIOR, A. Arte da animação: Técnica e estética através da história. São Paulo: Senac, 2005.

KRESS, G.; VAN LEEUWEN, T. Reading images: the grammar of visual design. London: Routledge, 2006.

PUJOL, R. M. Didáctica de las ciencias en la educación primaria. Madrid: síntesiseducación, 2007.

PIMENTA, S.M.O; SANTOS, Z. B. Recorte - Revista eletrônica do mestrado em letras Universidade Vale do Rio Verde. Volume 7, 2010.

RODRIGUES, G.B.A. Insetos na escola: Um estudo sobre a representação de formigas nos anos iniciais do ensino fundamental. Dissertação - Programa de Pós Graduação em Educação da Universidade Federal de Ouro Preto, 2019.

TRIPLEHORN, C. A. \& JOHNSON, N. F. An introduction to the study of insects. 7. ed. USA: Thomson - Brooks / Cole, 2005.

SALGADO, R. G. Ser criança e Herói no Jogo e na vida: a infância contemporânea, o brincar e os desenhos animados. Tese - Faculdade de Psicologia, PUC-Rio, Rio de Janeiro, 2005.

VIZACHRI, T. R. Animais humanos ou humanos animais?: Um estudo sobre a representação dos animais antropomorfizados em cultura. Dissertação. Programa de Pós-Graduação em 
Estudos Culturais, Escola de Artes, Ciências e Humanidades, Universidade de São Paulo, São Paulo, 2014.

\section{Animações:}

Formiga atômica. Disponível em: $<$ http://vimeo.com/13726978> . Acesso em: 12 nov. 2018.

Formiguinhaz. Disponível em $<$ https://www.youtube.com/watch? $\mathrm{v}=\mathrm{LgFNCqfHIiM}>$ Acesso em 12 de agosto de 2018.

Vida de inseto. Disponível em: $<$ https://www.youtube.com/watch? $\mathrm{v}=\mathrm{mLVtL}$ e-6nc $>$ Acesso em 18 de setembro de 2018.

Lucas: um intruso no formigueiro. Disponível em $<$ https://www.youtube.com/watch? $\mathrm{v}=\mathrm{V}$ Wc2Ri900A $>$ Acesso em 01 de setembro de 2018.

Minúsculos: Disponível em $<$ https://www.youtube.com/watch?v=8-k7IqiGOq4. $>$ Acesso em abril de 2018.

\section{Sites:}

http://www.tvsinopse.kinghost.net/f/formiga\%20atomica.htm. Acesso em: 12 nov. 2018.

https://www.oficinadanet.com.br/post/13723-por-que-as-formigas-conseguem-carregar-tantopeso. Acesso em: 12 nov. 2018.

https://omelete.uol.com.br/filmes/formiguinhaz/.Acesso em: 12 nov. 2018.

https://desenhosanimado5.wordpress.com/a-historia-do-desenho-animado/. Acesso em: 12 nov. 2018.

\section{NOTAS}

\section{AGRADECIMENTOS}

Pró-Reitoria de Pesquisa da Universidade Federal de Ouro Preto.

FINANCIAMENTO

Pró-Reitoria de Pesquisa da Universidade Federal de Ouro Preto.

\section{CONTRIBUIÇÕES DE AUTORIA}

Resumo/Abstract/Resumen: Sheila Alves de Almeida, Marco Antônio Alves Carneiro, Orlando Gomes Aguiar e Maykon Passos Cristiano

Introdução: Sheila Alves de Almeida, Marco Antônio Alves Carneiro, Orlando Gomes Aguiar e Maykon Passos Cristiano

Referencial teórico: Sheila Alves de Almeida, Marco Antônio Alves Carneiro, Orlando Gomes Aguiar e Maykon Passos Cristiano

Análise de dados: Sheila Alves de Almeida, Marco Antônio Alves Carneiro, Orlando Gomes Aguiar e Maykon Passos Cristiano 
Discussão dos resultados: Sheila Alves de Almeida, Marco Antônio Alves Carneiro, Orlando Gomes Aguiar e Maykon Passos Cristiano

Conclusão e considerações finais: Sheila Alves de Almeida, Marco Antônio Alves Carneiro, Orlando Gomes Aguiar e Maykon Passos Cristiano

Referências: Sheila Alves de Almeida, Marco Antônio Alves Carneiro, Orlando Gomes Aguiar e Maykon Passos Cristiano

Revisão do manuscrito: Sheila Alves de Almeida, Marco Antônio Alves Carneiro, Orlando Gomes Aguiar e Maykon Passos Cristiano

Aprovação da versão final publicada: Sheila Alves de Almeida, Marco Antônio Alves Carneiro, Orlando Gomes Aguiar e Maykon Passos Cristiano

\section{CONFLITOS DE INTERESSE}

Os autores declararam não haver nenhum conflito de interesse de ordem pessoal, comercial, acadêmico, político e financeiro referente a este manuscrito.

\section{DISPONIBILIDADE DE DADOS DE PESQUISA}

O conjunto de dados que dá suporte aos resultados da pesquisa foi publicado no próprio artigo.

\section{CONSENTIMENTO DE USO DE IMAGEM}

Não se aplica.

\section{APROVAÇÃO DE COMITÊ DE ÉTICA EM PESQUISA \\ Não se aplica.}

\section{COMO CITAR - ABNT}

ALMEIDA, Sheila Alves de; CARNEIRO, Marco Antônio Alves; AGUIAR, Orlando Gomes; CRISTIANO, Maykon Passos. De Minúsculos Titãs a Legionários que queimam: A representação de formigas nas animações infantis. REAMEC - Rede Amazônica de Educação em Ciências e Matemática. Cuiabá, v. 9, n. 1, e21007, janeiro-abril, 2021. DOI: 10.26571/reamec.v9i1.11201.

\section{COMO CITAR - APA}

ALMEIDA, S. A.; CARNEIRO, M. A. A.; AGUIAR, O. G., \& CRISTIANO, M. P. (2021). De Minúsculos Titãs a Legionários que queimam: A representação de formigas nas animações infantis. REAMEC - Rede Amazônica de Educação em Ciências e Matemática, 9 (1), e21007. DOI: 10.26571/reamec.v9i1.11201.

\section{LICENCCA DE USO}

Licenciado sob a Licença Creative Commons Attribution-NonCommercial 4.0 International (CC BY-NC 4.0). Esta licença permite compartilhar, copiar, redistibuir o manuscrito em qualquer meio ou formato. Além disso, permite adaptar, remixar, transformar e construir sobre o material, desde que seja atribuído o devido crédito de autoria e publicação inicial neste periódico.

\section{DIREITOS AUTORAIS}

Os direitos autorais são mantidos pelos autores, os quais concedem à Revista REAMEC - Rede Amazônica de Educação em Ciências e Matemática - os direitos exclusivos de primeira publicação. Os autores não serão remunerados pela publicação de trabalhos neste periódico. Os autores têm autorização para assumir contratos adicionais separadamente, para distribuição não exclusiva da versão do trabalho publicada neste periódico (ex.: publicar em repositório institucional, em site pessoal, publicar uma tradução, ou como capítulo de livro), com reconhecimento de autoria e publicação inicial neste periódico. Os editores da Revista têm o direito de proceder a ajustes textuais e de adequação às normas da publicação.

\section{PUBLISHER}

Universidade Federal de Mato Grosso. Programa de Pós-graduação em Educação em Ciências e Matemática (PPGECEM) da Rede Amazônica de Educação em Ciências e Matemática (REAMEC). Publicação no Portal de Periódicos UFMT. As ideias expressadas neste artigo são de responsabilidade de seus autores, não representando, necessariamente, a opinião dos editores ou da referida universidade. 


\section{EDITOR}

Marcel Thiago Damasceno Ribeiro

\section{HISTÓRICO}

Submetido: 29 de setembro de 2020 .

Aprovado: 28 de novembro de 2020.

Publicado: 17 de janeiro de 2021. 